\title{
APPLICATION OF STABILITY CHARTS AND RELIABILITY CONCEPTS FOR SIMPLIFIED ANALYSIS OF A VOID IN SOIL OVERLYING KARST BEDROCK
}

\author{
Timothy C. Siegel, PE, GE, DGE \\ Dan Brown and Associates, PC, 1808 Northshore Hills Blvd., Knoxville, Tennessee 37922 USA, \\ tsiegel@danbrownandassociates.com
}

\section{Danner F. Drake, PE}

CDG Engineers \& Associates, Inc., 1830 Hartford Hwy., Dothan, Alabama 36301 USA, ddrake@cdge.com

\section{Eric C. Drumm, PE, PhD}

Dept. of Biosystems Engineering and Soil Science, The University of Tennessee, Knoxville, Tennessee 37996-4531

USA,edrumm@utk.edu

\begin{abstract}
The karst belt stretching from Alabama to New England is dominated by limestone/dolostone rocks which are observed to weather in-place forming a layer of residual clay soil above a highly weathered rock surface. As part of the natural weathering process, subterranean voids frequently develop in the overburden soil, which can lead to surface subsidence or collapse (sinkholes). Furthermore, construction activities can promote instability, especially where a portion of the soil overburden is removed. A rational method for addressing the potential for void collapse may involve the use of simplified charts to perform probabilistic analysis for likely ranges of void and soil conditions. This paper demonstrates the application of simplified stability charts and reliability concepts for evaluating the collapse potential of voids within the soil overlying the rock surface.
\end{abstract}

\section{Introduction}

Subterranean voids in the bedrock and in the overburden soil develop as part of the natural weathering process in the karst belt stretching from Alabama to New England, where the underlying limestone/dolostone rocks are observed to weather in-place forming a layer of residual clay soil above a highly weathered rock surface. A methodology for evaluating the static stability of discrete voids (i.e., caves) within shallow rock is presented by Siegel et al. (2001). Drumm and Yang, (2005) and Drumm et al. (2009) developed simplified charts for evaluating the static stability of a void within the soil overburden. However, there are aspects, such as the determination of representative void sizes and geometry, that present difficulties in characterizing the risk of void collapse. To overcome such difficulties, simplified stability charts may be combined with reliability concepts to characterize the risk of collapse of a void in the soil overlying the rock surface.

\section{Simplified Charts for Soil Stability}

Stability charts are widely used for the evaluation of soil slopes (Taylor, 1937; Bishop and Morgenstern, 1960) where the charts were developed in terms of the slope height and inclination, and the soil shear strength is expressed in terms of the soil cohesion intercept, c, and friction angle $\varphi$. These stability charts are typically presented in terms of a dimensionless stability number, $\mathrm{N}$, which is often defined by Equation 1 .

$$
N=\frac{\gamma H}{c}
$$

where $\mathrm{N}$ is a dimensionless stability number, $\gamma$ is the unit weight of the soil, $\mathrm{H}$ is the height of the slope, and $\mathrm{c}$ is the cohesion component of the soil shear strength. Typically, the charts allow the potential for failure to be expressed in terms of a factor-of-safety (FS) or the ratio of the available soil strength to the strength required to maintain stability.

$$
F S=\frac{c}{c_{d}}=\frac{\tan \phi}{\tan \phi_{\mathrm{d}}}
$$

where the parameters $c_{d}$ and $\varphi_{d}$ are the corresponding values of the cohesion intercept and friction angle required to maintain equilibrium. Using some of the concepts originally applied to soil slopes, Drumm et al. (2009) prepared simplified charts for the evaluation of the stability of a void in the soil overlying the rock surface. 


\section{Stability Chart for Void in Soil}

A subterranean void will be stable where the overlying soil is capable of re-distributing the stresses to competent material below. The ability of the soil to redistribute the stresses will depend on the void geometry, the soil thickness, the soil strength and the magnitude of the surcharge load, if present.

\section{Characteristic Subsurface Profile}

The characteristic subsurface profile in a highly weathered, clay-mantled karst terrain is described by Sowers (1996). From the ground surface, there is a blanket of soil that is composed of the insoluble portion of the karst bedrock. The upper residual soil is often stiff from overconsolidation as a result of exposure to multiple cycles of wetting and drying. With depth, the residual soil generally increases in water content and decreases in stiffness and strength. Competent karst bedrock (e.g., limestone) typically exhibits high strength but contains slots, caves, and other openings created by the solutioning process. Voids in the soil or "domes" are created as the soil ravels and/or migrates downward into slots, caves, and other openings in the underlying rock (Figure 1).

\section{Finite Element Model}

The dimensionless chart developed by Drumm et al. (2009) to evaluate the stability of a void in soil overlying karst bedrock is based on the results of finite element analyses. The analyses were conducted for a range of hypothetical soil properties and void geometries expressed in terms of the ratio of an assumed hemispherical void diameter (D) to soil overburden thickness above the void (h). The idealized model and terms used in the finite element analyses are shown in Figure 2.

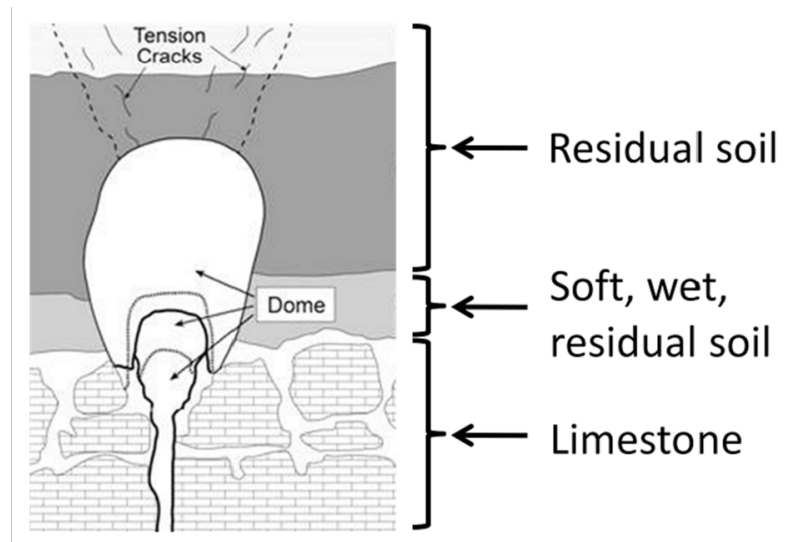

Figure 1. Conceptual subsurface profile in karst with an enlarging void in the residual soil (Sowers, 1996).

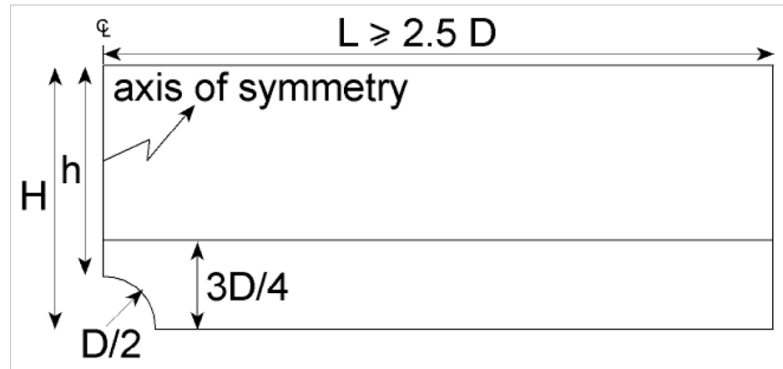

Figure 2. Axisymmetric idealization of void in soil over rock (Drumm et al., 2009).

Assumptions made in the finite element analyses are summarized in the following:

1. The geometric conditions around the void were approximated by a two-dimensional axisymmetric model, implying a hemispherical void of diameter D. The soil was assumed to be homogeneous except for analyses that assume a weaker soil layer with a thickness of 3D/4;

2. The stiffness of the rock was much greater (typically $10^{4}$ times) than that of the soil and, as a result, the rock was considered to provide a rigid support at the base of the soil. Therefore, the rock surface was represented by a fixed boundary in the model;

3. The lateral boundary of the finite element model was confirmed to have no effect on stability. The lateral extent (L) for the largest diameter was extended until it had negligible effect on stability. The results indicated that there was no boundary effect for an $\mathrm{L} / \mathrm{D}>2.5$ for $\mathrm{h} / \mathrm{D}=0.5$;

4. The majority of the analyses were performed with a constant soil unit weight of $17.7 \mathrm{kN} /$ $\mathrm{m}^{3}\left(112.8 \mathrm{lb} / \mathrm{ft}^{3}\right)$. However, the soil unit weight was incorporated into the dimensionless terms;

5. The soil strength was represented using the MohrCoulomb elastic-plastic model, which allows the soil to act as an elastic solid at stress levels less than the strength, and allows the soil to flow plastically at stress levels equal to the strength. The use of a Mohr-Coulomb failure criterion inherently assumes that the intermediate principle stress $\sigma_{2}\left(\sigma_{1} \geq \sigma_{2} \geq \sigma_{3}\right)$ has no influence on the failure condition (Chen and Liu, 1990) and the failure is defined by Equation 3 .

$$
\tau=c+\sigma \tan \varphi
$$


where strength parameters $\mathrm{c}$ and $\phi$ represent the cohesion intercept and angle of internal friction, respectively, and $\sigma$ is the normal stress. A nonassociative flow rule was assumed with a zero dilation angle $(\psi=0)$ which results in the soil experiencing zero volume change during yield. The tensile strength was assumed to be $20 \%$ of the undrained shear strength values $\left(c_{u}\right)$. This assumption, while somewhat arbitrary, allows for a variation in tensile strength in proportion to cu while maintaining the dimensionless stability factors;

6. The elastic modulus of the soil (E) was assumed to be $22 \mathrm{MPa}$ (4.6 x $105 \mathrm{psf}$ ). Although the stability is not sensitive to the elastic modulus provided it is a constant, this value is consistent with published correlations with the undrained shear strength (Das, 1999).

$$
E=440 c_{u}
$$

where $c_{u}$ is the initial value of undrained shear strength used in the analysis. The deformation field and the surface subsidence were not considered;

7. The Poisson's ratio was assumed to be 0.3 which is consistent with published values for a variety of soil types (Bowles, 1988). In general, the results of the evaluation are somewhat sensitive to Poisson's ratio;

8. The initial field stresses were represented by restraining the soil around the void while applying the gravitational force with a stress ratio $\mathrm{K}_{\mathrm{o}}$ according to Equation 5

$$
K_{o}=1-\sin \varphi^{\prime}
$$

after which the soil around the void was released allowing deformation, and;

9. The water table is assumed to remain constant at a position below the top of the rock surface. This assumption results in the greatest effective stress for any of the conditions considered. Enlargement of the void due to soil loss is neglected and seepage effects on stability are not considered.

\section{Determination of Collapse Load}

The dimensionless ratio $h / D$ was used to define the subsurface geometry where $\mathrm{h}$ is the minimum soil thickness over the $\operatorname{void}(h=H-D / 2)$ and $\mathrm{D}$ is the void diameter (Figure 2$)$.
The dimensionless stability number $\left(\mathrm{N}_{\mathrm{c}}\right)$ was determined by applying the shear strength reduction (SSR) method proposed by Zheng et al. (2006). In the SSR method, which is widely used in both soil and rock engineering (Griffiths and Lane, 1999; Swan and Seo, 1999), the strength parameters of the model are reduced by a strength reduction factor (SRF), such that

$$
\tau=\frac{\mathrm{c}+\sigma \tan \varphi}{\mathrm{SRF}}
$$

the finite element analysis is conducted with incrementally increasing values of SRF until the analysis does not converge to equilibrium. This determines the critical SRF and represents a factor-of-safety of unity. The critical SRF can be used to calculate the critical strength and $\mathrm{N}_{\mathrm{c}}$.

\section{Soil Friction Angle}

Analysis using only undrained shear strength may be considered representative of short term conditions. To extend the analysis to long term (or effective stress) conditions, the stability was also evaluated using the similar methodology with a value of $\varphi^{\prime}>0$. The approach used for $\varphi=0$ was repeated to determine the value of $c$ corresponding to a convergent solution for values of $\varphi^{\prime}=10^{\circ}, 20^{\circ}$, and $30^{\circ}$ with the SRF applied the tan $\varphi^{\prime}$ and the initial stress ratio following Eq. (6). The stability chart is presented in Figure 3.

\section{Inverted Strength Profile}

Rather than having a profile where the shear strength increases with depth (as is the case in most geologic settings), karst often exhibits a soft zone above the rock surface. This is often referred to as an inverted residual strength profile (Sowers, 1996). To consider the inverted strength profile, analyses were performed for undrained conditions $(\varphi=0)$ with the lower $3 \mathrm{D} / 4$ portion of the soil profile assigned a reduced undrained shear strength $\left(\mathrm{c}^{*}\right)$.

$$
c^{*}=\alpha c
$$

where $\mathrm{c}^{*}$ is the reduced undrained shear strength for the bottom 3D/4 part of the soil layer; $c$ is the undrained shear strength of the soil; and $\alpha$ is the inverted strength factor. Figure 3 includes the stability numbers for undrained conditions with inverted strength factors of $0.25,0.5$, and 1.0 . 


\section{Functional Form of Stability Chart}

To allow direct use of the stability chart shown in Figure 3 , a linear function was fitted to the curves using the following form.

$$
\mathrm{N}_{\mathrm{c} \phi}=\mathrm{a}(\mathrm{h} / \mathrm{D})^{3}-\mathrm{b}(\mathrm{h} / \mathrm{D})^{2}+\mathrm{c}(\mathrm{h} / \mathrm{D})+\mathrm{d}
$$

where $\mathrm{a}, \mathrm{b}, \mathrm{c}$ and $\mathrm{d}$ are constants determined by regression analyses. The values of constants $\mathrm{a}, \mathrm{b}, \mathrm{c}$, and $\mathrm{d}$ for a range of values of $\phi$ and $\alpha$ are presented in Table 1 .

\section{Reliability Concepts}

Reliability concepts provide a useful framework for analysis where there is uncertainty in the parameters involved (Harr, 1987; Whitman, 1996). For application of the stability chart presented herein, it is proposed to incorporate the approach proposed by Duncan (2000) which allows an assessment of the reliability of the factor-of-safety and calculation of the probability of collapse using the following steps.

1. Estimate the standard deviations of the parameters involved. Duncan (2000) suggests applying the "threesigma rule" which makes use of the fact that $99.73 \%$ of all values of a normally distributed parameter fall within three standard deviations of the average. The standard deviation is computed using the Equation 9.

$$
\sigma=\frac{H C V-L C V}{6}
$$

where $\mathrm{HCV}$ is the highest conceivable value and $\mathrm{LCV}$ is the lowest conceivable value.

2. Use the Taylor series technique (Wolff, 1994; U.S. Army Corps of Engineers, 1997 and 1998) to estimate the standard deviation and coefficient of variation of the factor-of-safety.

3. Determine the "probability of failure" and the reliability of the factor-of-safety based on a lognormal distribution of values. Duncan (2000) presents a table that summarizes the mathematical results necessary to apply a lognormal distribution.

Table 1. Constants and $r^{2}$ values for curves in Figure 3 (Drumm et al., 2009).

\begin{tabular}{llrrrrr}
\multicolumn{7}{c}{ Constants a, b, c and d along with r2 } \\
& \multicolumn{1}{c}{$\mathrm{a}$} & \multicolumn{1}{c}{$\mathrm{b}$} & $\mathrm{c}$ & $\mathrm{D}$ & $\mathrm{r} 2$ \\
\hline \multirow{4}{*}{$\left(^{\circ}\right)$} & 0 & 0.0013 & 0.0766 & 1.9944 & 1.8914 & 0.9982 \\
& 10 & 0.0004 & 0.0353 & 2.0744 & 0.6521 & 0.9990 \\
& 20 & -0.0008 & -0.0101 & 2.6131 & 0.6484 & 0.9994 \\
& 30 & -0.0005 & -0.0033 & 3.2346 & 0.6168 & 0.9987 \\
\hline$\alpha$ & 1.0 & 0.0013 & 0.0766 & 1.9944 & 1.8914 & 0.9982 \\
$\Phi=0$ & 0.5 & 0.0014 & 0.0826 & 1.6923 & 0.6220 & 0.9959 \\
& 0.25 & 0.0006 & 0.0400 & 0.8339 & 0.3145 & 0.9954 \\
\hline
\end{tabular}

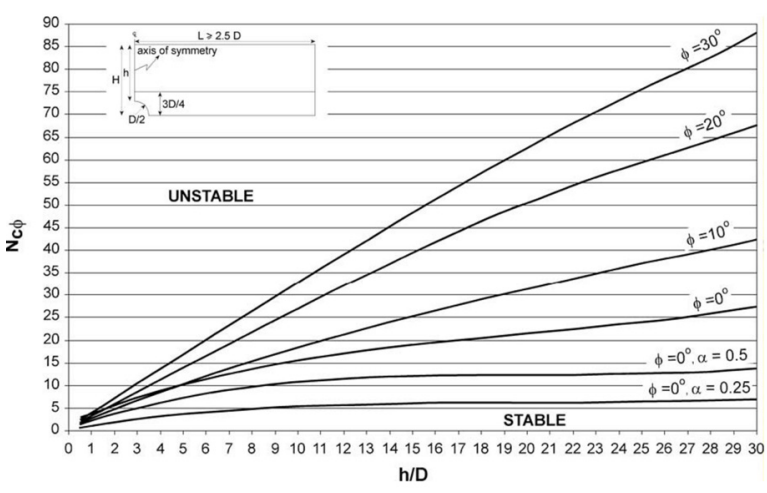

Figure 3. Stability chart for estimating $\mathrm{N}_{c_{\phi}}$ for a void in soil overlying rock (Drumm et al., 2009).

\section{Case History: Landfill in Karst Terrain}

The simplified stability charts and reliability concepts presented herein were used to evaluate the collapse potential of voids within the soil during the permitting activities for a landfill in a karst region in northeastern Alabama. The project information is summarized in the following paragraphs.

\section{Geologic and Subsurface Conditions}

Published maps show that site is located within the Appalachian Plateau (Hunt, 1967) and that the bedrock is light gray and light brown, locally sandy dolostone, dolomitic limestone and limestone of the Knox Group Undifferentiated.

The geotechnical exploration consisted of soil test borings, air-track probes and multi-electrode electrical resistivity. On the basis of the exploration results, the subsurface conditions are characterized by a thick layer of residual soil consisting of very stiff (average SPT N of 28), sandy clays and silts with interbedded seams of clayey gravel (chert) and sand. The soil thickness ranged from approximately $5 \frac{1}{2}$ to $30 \frac{1}{2} \mathrm{~m}$ (18 1/2 to 100 feet). There was a slight decrease in SPT N from 20 to $50 \mathrm{ft}$ below the ground surface.

The soil strength was characterized based on the results of consolidated-isotropically, undrained compression triaxial tests that were performed on soil samples obtained in similar geologic and geotechnical conditions. The strength test results are summarized in Figures 4 (total stress or undrained strength) and 5 (effective stress or drained strength).

Multi-electrode electrical testing was performed in an effort to identify landfill areas that may be underlain 
by a void within the soil. The method involves passing direct current through the earth between two electrodes and measuring the resulting voltage drop between an additional pair of electrodes (Roth and Nyquist, 2003). A typical resistivity profile is presented in Figure 6. Sharp contrasts or "anomalies" within the resistivity profile were considered potential subterranean voids.

\section{Void and Soil Parameters}

No voids were encountered within the test borings, including those that were drilled at "anomalies" (extremely high resistivity values or extremely low resistivity values) interpreted from the multi-electrode electrical resistivity testing. Considering the results of the geotechnical exploration and published data of doline diameter (Newton and Tanner, 1986; Martin, 1995; Qubain et al., 1995, Abdulla and Mollah, 1997; Mishu et al., 1997; Smith, 1997; and Thomas and Roth, 1997), a void diameter of 6 feet was considered to be a realistic, conservative assumption. It was anticipated that voids having a diameter greater than 6 feet, if present, would be detected during the resistivity testing and borings that target resistivity anomalies. This would allow application of corrective actions (e.g., cap grouting) to significant voids. Optionally, the range of void diameter (or any other variable) could have been explicitly considered in the reliability analysis.

The soil unit weight ranged from 18.0 to $19.9 \mathrm{kN} / \mathrm{m}^{3}(114.5$ to $126.5 \mathrm{pcf}$ ) and averaged $18.9 \mathrm{kN} / \mathrm{m}^{3}$ (120.5 pcf). The soil thickness (i.e., the overburden height $(\mathrm{h})$ ranged from 7.8 to $22.5 \mathrm{~m}$ (25.6 to $73.8 \mathrm{feet})$ and averaged $15.2 \mathrm{~m}$ (49.7 feet).

The undrained shear strength ranged from 40.2 to $110.6 \mathrm{kPa}$ (840 psf to $2310 \mathrm{psf}$ ) and averaged 74.2
$\mathrm{kPa}$ (1550 psf). An inverted strength factor $(\alpha)$ of 0.6 was applied for undrained conditions. The effective friction angle ranged from 20.4 to 20.9 degrees and averaged 20.6 degrees. The effective cohesion ranged from 15.1 to $54.6 \mathrm{kPa}$ (324 to $1141 \mathrm{psf}$ ) and averaged $35.1 \mathrm{kPa}(733 \mathrm{psf})$.

\section{Probability of Void Collapse}

Following the Duncan approach (2000), the Taylor Series was used to compute the probability of void collapse for the conditions at the Alabama landfill. The method requires that factors-of-safety be determined where each parameter is individually increased and decreased one standard deviation (s.d.) from its "most likely value". A summary of factorsof-safety is presented in Table 2.The factors-of-safety for the most likely values (MLV) are 2.74 and 2.79 for total stress conditions and effective stress conditions, respectively. The standard deviations of the calculated factors-of-safety are 1.46 and 1.57 , respectively. The coefficient of variation (VF) for the each factor-ofsafety may be determined using Equation 10.

$$
V_{F}=\frac{s \cdot d_{\cdot F}}{F O S_{M L V}}
$$

The computed VF values are 53.3\% (total stress conditions) and $56.2 \%$ (effective stress conditions). The lognormal reliability index $\left(\beta_{\mathrm{LN}}\right)$ values are calculated using Equation 11.

$$
\beta_{L N}=\frac{\ln \left(\frac{F O S_{M L V}}{\sqrt{1+V_{F}^{2}}}\right.}{\sqrt{\ln \left(1+V_{F}^{2}\right.}}
$$

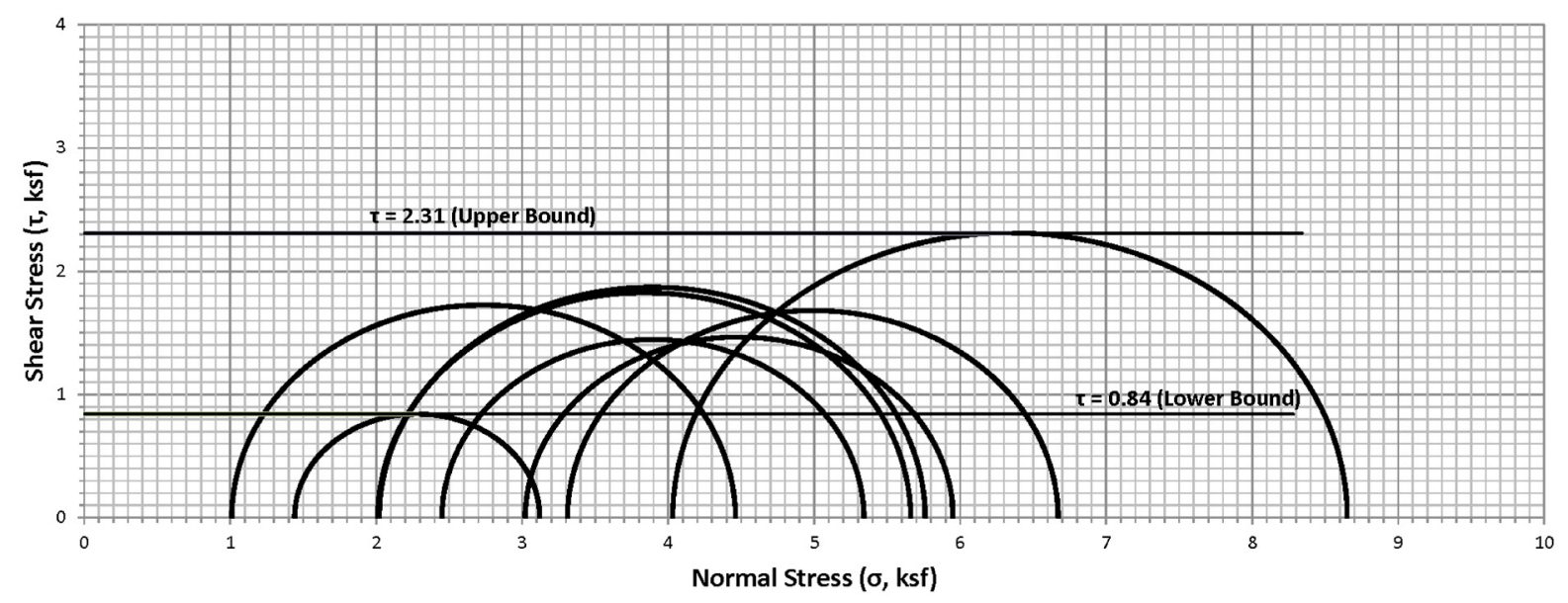

Figure 4. Total stress strength data $(1 \mathrm{ks} f=47.88 \mathrm{kPa})$. 


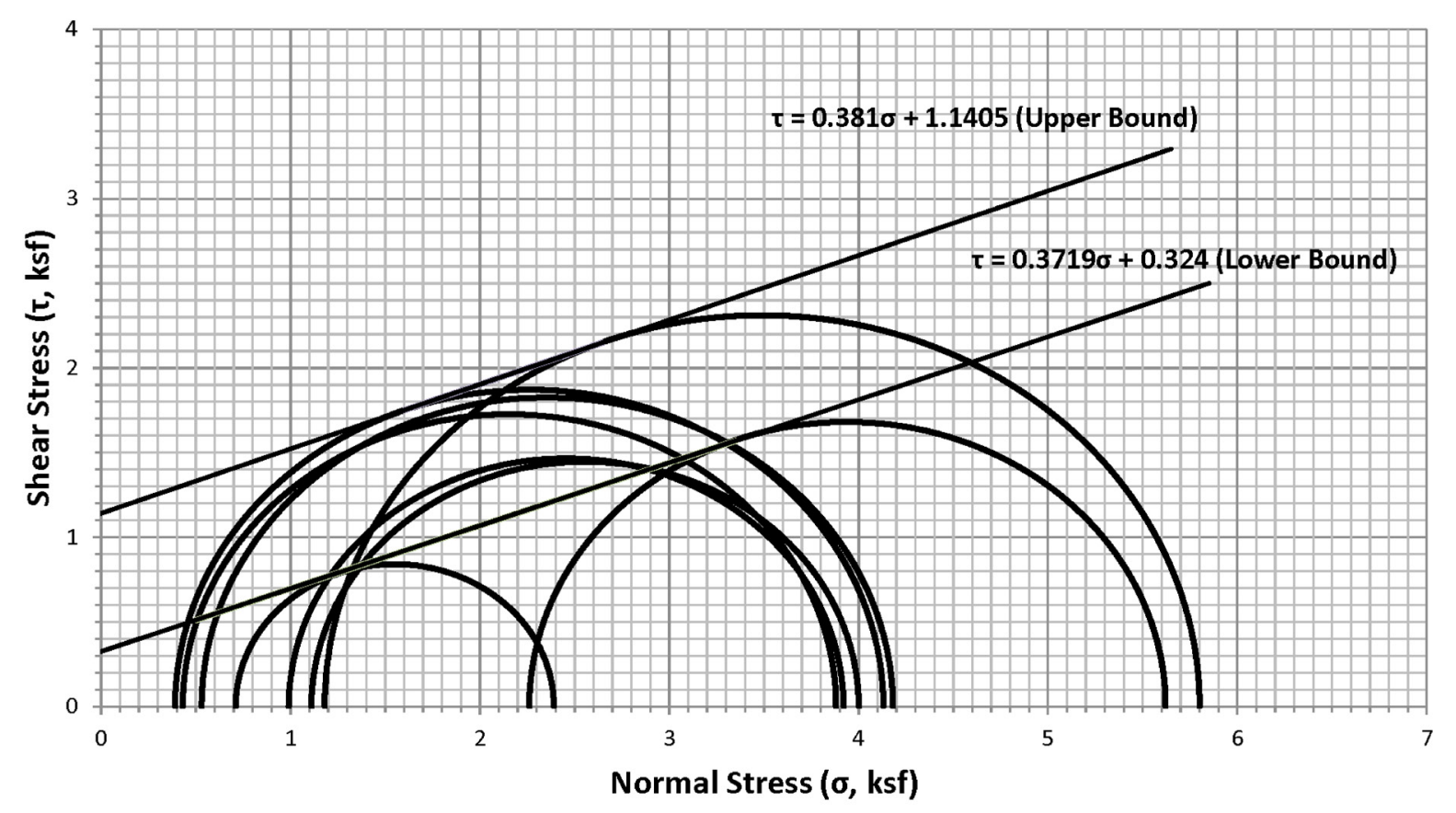

Figure 5. Effective stress strength data ( $1 \mathrm{ksf}=47.88 \mathrm{kPa})$.

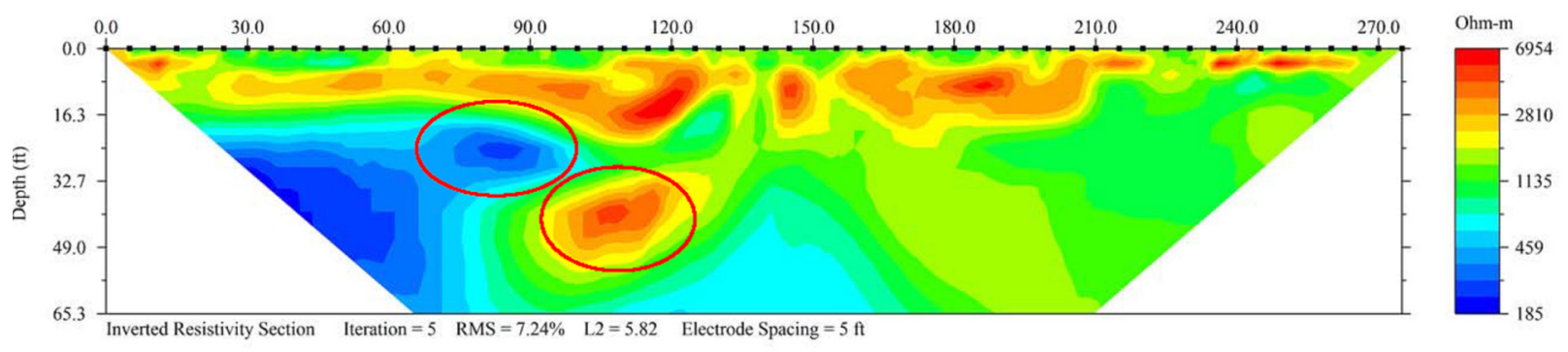

Figure 6. Typical resistivity profile ( $1 \mathrm{ft}=0.305 \mathrm{~m}$ ) (Examples of "anomalies" noted by red circles).

and the probability of void collapse $\left(\mathrm{P}_{\mathrm{f}}\right)$ can be calculated using Equation 12.

$$
P_{F}=1-\beta_{L N}
$$

The calculated probabilities of collapse are 3.9\% (total stress conditions) and $4.5 \%$ (effective stress conditions). According to Vick (2002), these values correspond to conditions where void collapse is between "almost impossible" to "very improbable".

\section{Conclusions}

Subterranean voids in the overburden soil develop as part of the natural weathering process in karst terrain. Even in cases where the soil strength is well characterized, there is often uncertainty with respect to the size and geometry of the potential subterranean voids. Furthermore, construction activities can promote instability, especially where a portion of the soil overburden is removed. A rational method for addressing the potential for void collapse involves the use of simplified charts by

Table 2. Summary of factors-of-safety.

\begin{tabular}{|c|c|c|c|c|}
\hline \multicolumn{5}{|c|}{ Total Stress Conditions } \\
\hline Variable & $\mathrm{c}$ & $\mathrm{h}$ & $\mathrm{g}$ & \\
\hline FOS (+s.d.) & 4.09 & 2.21 & 2.61 & \\
\hline FOS (-s.d.) & 1.49 & 3.51 & 2.89 & \\
\hline$\Delta$ FOS & 2.60 & 1.30 & 0.28 & \\
\hline \multicolumn{5}{|c|}{ Effective Stress Conditions } \\
\hline Variable & $\mathrm{c}^{\prime}$ & $\varphi^{\prime}$ & $\mathrm{h}$ & $\gamma$ \\
\hline FOS (+s.d.) & 4.35 & 2.81 & 2.74 & 2.66 \\
\hline FOS (-s.d.) & 1.23 & 2.78 & 2.87 & 2.94 \\
\hline$\Delta$ FOS & 3.12 & 0.03 & 0.13 & 0.28 \\
\hline
\end{tabular}


Drumm et al. (2009) to perform probabilistic analysis for likely ranges of void and soil conditions. In such a way, the potential for void collapse may be described in both numerically (i.e., probability of collapse) and verbally (e.g., very improbable, almost improbable, very unlikely...). The example presented herein represents a snapshot of a hypothetical void under static condition. It is important to note that multiple analyses may be required to fully characterize the risk of void collapse.

\section{References}

Abdulla WA, Mollah MA. 1997. Sinkhole investigation: An on-going case study in Kuwait. In Beck BF, Stephenson, JB, editors. Karst Geohazards: Engineering and Environmental Problems in Karst Terrane, Proceedings of the 6th Multidisciplinary Conference on Sinkholes and the Engineering and Environmental Impacts of Karst; Apr. 6-9; Springfield, Missouri. Brookfield (VT): A.A. Balkema, p. 329-350.

Bishop AW, Morgenstern NR. 1960. Stability coefficients for earth slopes. Geotechnique 10 (4): 129-150.

Bowles JE. 1988. Foundation design and analysis. McGraw-Hill.

Chen WF, Liu XL. 1990. Limit analysis in soil mechanics. New York (NY): Elsevier Science.

Das BM. 1999. Principles of foundation engineering. 4th ed. Boston (MA): PWS-Kent.

Drumm EC, Aktürk O, Akgün H, Tutluoğlu L. 2009. Stability charts for the collapse of residual soil in karst. Journal of Geotechnical and Geoenvironmental Engineering 135 (7): 925-931.

Drumm EC, Yang MZ. 2005. Preliminary screening of residual soil stability in karst terrain. Journal of Environmental \& Engineering Geoscience XI(1): 29-42.

Duncan JM. 2000. Factor of safety and reliability in geotechnical engineering. Journal of Geotechnical and Geoenvironmental Engineering 126(4): 307-316.

Griffiths DV, Lane PA. 1999. Slope stability analysis by finite elements. Geotechnique 49(3): 387-403.

Harr ME. 1986. Reliability-based design in civil engineering. New York (NY): McGraw Hill Book Company.

Hunt CB. 1967. Physiography of the United States. San Francisco (CA): W.H. Freeman and Company.

Martin AD. 1995. Maryland Route 31 sinkhole. In: Beck BF, editor. Karst Geohazards: Engineering and Environmental Problems in Karst Terrane: Proceedings of the 5th Multidisciplinary Conference on Sinkholes and the Engineering and Environmental Impacts of Karst. Brookfield (VT): A.A. Balkema. P. 319-334.
Mishu LP, Godfrey JD, and Mishu JR. 1997. Foundation remedies for residential construction over karst limestone in Nashville, Tennessee. In Beck BF, Stephenson, JB, editors. Karst Geohazards: Engineering and Environmental Problems in Karst Terrane, Proceedings of the 6th Multidisciplinary Conference on Sinkholes and the Engineering and Environmental Impacts of Karst; Apr. 6-9; Springfield, Missouri. Brookfield (VT): A.A. Balkema, p. 319-323.

Newton JG, Tanner JM. 1986. Regional inventory of karst activity in the Valley and Ridge Province, Eastern Tennessee, Phase 1. Oak Ridge National Laboratory ORNL/Sub/11-79811/1.

Qubain BS, Seksinsky EJ, Aldin EG. 1997. Techniques to investigate and remedy sinkholes. In Beck BF, Stephenson, JB, editors. Karst Geohazards: Engineering and Environmental Problems in Karst Terrane, Proceedings of the 6th Multidisciplinary Conference on Sinkholes and the Engineering and Environmental Impacts of Karst; Apr. 6-9; Springfield, Missouri. Brookfield (VT): A.A. Balkema, p. 341-347.

Roth MJS, Nyquist JE. 2003. Evaluation of multielectrode earth resistivity testing in karst. Geotechnical Testing Journal 26 (2): 1-12.

Siegel TC, Belgeri JJ, McCrackin DM. 2001. Case history of east Tennessee karst: Static stability of shallow caves. Foundations and Ground Improvement, ASCE, GSP 113: 858-870.

Smith JT. 1997. Sinkhole damage investigations for the insurance industry in west-central Florida. In Beck BF, Stephenson, JB, editors. Karst Geohazards: Engineering and Environmental Problems in Karst Terrane, Proceedings of the 6th Multidisciplinary Conference on Sinkholes and the Engineering and Environmental Impacts of Karst; Apr. 6-9; Springfield, Missouri. Brookfield (VT): A.A. Balkema, p. 299-304.

Sowers GF. 1996. Building on sinkholes: Design and construction of foundations in karst terrain, ASCE, $202 \mathrm{p}$.

Swan CC, Seo YK. 1999. Limit state analysis of earthen slopes using dual continuum/FEM approaches. International Journal of Numerical and Analytical Methods in Geomechanics 23(12): 1359-1371.

Taylor DW. 1937. Stability of earth slopes. Journal of the Boston Society of Civil Engineering, 24-31, Reprinted in: Contributions to Soil Mechanics 1925 to 1940 , Boston Society of Civil Engineers, 337-386. 
Thomas B., Roth JS. 1997. Site characterization for sinkholes in Pennsylvania and New Jersey. In Beck BF, Stephenson, JB, editors. Karst Geohazards: Engineering and Environmental Problems in Karst Terrane, Proceedings of the 6th Multidisciplinary Conference on Sinkholes and the Engineering and Environmental Impacts of Karst; Apr. 6-9; Springfield, Missouri. Brookfield (VT): A.A. Balkema, p. 281-286.

U.S. Army Corps of Engineers. 1997. Engineering and design introduction to probability and reliability methods for use in geotechnical engineering. Department of the Army Engineering Technical Letter No. 1110-2-547.

Vick SG. 2002. Degrees of belief: Subjective probability and engineering judgment. ASCE.

Whitman RV. 1996. Organizing and evaluating uncertainty in geotechnical engineering. Uncertainty in the Geologic Environment: From Theory to Practice, ASCE, GSP 58: 1-28.

Wolff TF. 1994. Evaluating the reliability of levees. Rep. Res. Proj.: Reliability of Existing Levees, prepared for the U.S. Army Engineer Waterways Experiment Station Geotechnical Laboratory, Vicksburg, MS.

Zheng H, Tham LG, Lui D. 2006. On two definitions of the factor-of-safety commonly used in the finite element slope stability analysis. Computers and Geotechnics 33 (3): 188-195. 